\title{
Effects of shading on the growth and leaf photosynthetic characteristics of three forages in an apple orchard on the Loess Plateau of eastern Gansu, China
}

\author{
Mei Yang ${ }^{1}$, Minguo Liu ${ }^{1}$, Jiaoyun Lu ${ }^{1}$, Huimin Yang ${ }^{\text {Corresp. } 1}$ \\ ${ }^{1}$ State Key Laboratory of Grassland Agro-ecosystems, College of Pastoral Agriculture Science and Technology, Lanzhou University, Lanzhou, China \\ Corresponding Author: Huimin Yang \\ Email address: huimyang@|zu.edu.cn
}

Background. Inclusion of forage into the orchard is of great help to promote the use efficiency of resources, while shading from trees restricts forage growth and production in the Loess Plateau of China. This study was aimed to investigate how tree shading affected leaf trait, photosynthetic gas exchange and chlorophyll feature of forages under the tree in the orchard-forage system.

Methods. The shading treatments were set as partially cutting branches (reduced shading), normal fruit tree shading (normal shading) and normal tree shading plus sun-shading net (enhanced shading) in an apple orchard. Leaf trait, photosynthesis, chlorophyll component and fluorescence related parameters were measured with lucerne (Medicago sativa), white clover (Trifolium repens) and cocksfoot (Dactylis glomerata) which were sown under apple trees.

Results. Shading imposed significant impacts on the growth and leaf photosynthetic characteristics, while there were differences among species. Enhanced shading decreased leaf thickness, leaf dry matter content (LDMC) and leaf mass per unit area (LMA). Biomass accumulation decreased with enhanced shading in cocksfoot, but did not change in white clover and lucerne which had much lower biomass accumulation than cocksfoot. Enhanced shading reduced net photosynthetic rate (Pn) of white clover and lucerne, but rarely affected cocksfoot, while it decreased instantaneous water use efficiency (WUEi) of cocksfoot but had few effects on the other forages. Enhanced shading reduced leaf dark respiration rate $(\mathrm{Rd})$, light compensation point (LCP) and maximum assimilation rate. The Rd and LCP of cocksfoot were much lower than those of white clover and lucerne. Chlorophyll contents and chlorophyll a/b changed little with shading. Cocksfoot had the highest contents but lowest ratio. Maximum photochemical rate of photosystem II increased and non-photochemical quenching decreased with enhanced shading in cocksfoot, while did not change in the other forages.

Discussion. Leaf trait, photosynthetic gas exchange and chlorophyll feature were variously affected by species, shading and their interaction. Cocksfoot was more efficient than the other two forages in use of weakened light and more tolerant to tree shading. In the apple orchard, we recommend that reducing the density of apple tree or partially cutting branches together with selecting some shading-tolerant forages, i.e. cocksfoot, would be a practical option for the orchard-forage system in the Loess Plateau of China. 


\section{Effects of shading on the growth and leaf}

2 photosynthetic characteristics of three forages in an

3 apple orchard on the Loess Plateau of eastern Gansu,

4 China

6 Mei Yang, Minguo Liu, Jiaoyun Lu, Huimin Yang*

7 State Key Laboratory of Grassland Agro-ecosystems, College of Pastoral Agriculture Science

8 and Technology, Lanzhou University, Lanzhou, China

9

10

Corresponding Author:

11 Huimin Yang

12 Jiayuguanxi Road, Lanzhou, Gansu province, 730020, P. R. China

\section{Abstract}

Background. Inclusion of forage into the orchard is of great help to promote the use efficiency of resources, while shading from trees restricts forage growth and production in the Loess Plateau of China. This study was aimed to investigate how tree shading affected leaf trait, photosynthetic gas exchange and chlorophyll feature of forages under the tree in the orchardforage system.

Methods. The shading treatments were set as partially cutting branches (reduced shading), normal fruit tree shading (normal shading) and normal tree shading plus sun-shading net (enhanced shading) in an apple orchard. Leaf trait, photosynthesis, chlorophyll component and fluorescence related parameters were measured with lucerne (Medicago sativa), white clover (Trifolium repens) and cocksfoot (Dactylis glomerata) which were sown under apple trees. Results. Shading imposed significant impacts on the growth and leaf photosynthetic characteristics, while there were differences among species. Enhanced shading decreased leaf thickness, leaf dry matter content (LDMC) and leaf mass per unit area (LMA). Biomass accumulation decreased with enhanced shading in cocksfoot, but did not change in white clover and lucerne which had much lower biomass accumulation than cocksfoot. Enhanced shading reduced net photosynthetic rate (Pn) of white clover and lucerne, but rarely affected cocksfoot, while it decreased instantaneous water use efficiency (WUEi) of cocksfoot but had few effects on the other forages. Enhanced shading reduced leaf dark respiration rate (Rd), light compensation point (LCP) and maximum assimilation rate. The Rd and LCP of cocksfoot were much lower than those of white clover and lucerne. Chlorophyll contents and chlorophyll a/b changed little with shading. Cocksfoot had the highest contents but lowest ratio. Maximum photochemical rate of photosystem II increased and non-photochemical quenching decreased with enhanced shading in cocksfoot, while did not change in the other forages. 
39 Discussion. Leaf trait, photosynthetic gas exchange and chlorophyll feature were variously

40 affected by species, shading and their interaction. Cocksfoot was more efficient than the other

41 two forages in use of weakened light and more tolerant to tree shading. In the apple orchard, we

42 recommend that reducing the density of apple tree or partially cutting branches together with

43 selecting some shading-tolerant forages, i.e. cocksfoot, would be a practical option for the

44 orchard-forage system in the Loess Plateau of China.

45

46 Introduction

47 Traditional orchard performance with bare ground or simple tillage to the soil has led to serious soil erosion and low use efficiency of resources, such as light, soil water and nutrients (Shui et al., 2008). Inclusion of grass (and/or forage) into the orchard is an advanced management mode for orchard soil (Skroch \& Shribbs, 1986), offering a solution to deal with such issues, and has been widely used as an efficient conservation tillage in the orchard (Neves et al., 2010). However, the possible competition on soil water and nutrient between tree and grass under the tree has lit up some worries that sowing grass in the orchard might result in loss of fruit yield and quality, especially in some areas where water deficit and soil infertility happen a lot (Monteiro \& Lopes, 2007; Teravest et al., 2010), an example being the Loess Plateau of China. So how the grass roles in such an integrative system have attracted wide attention.

The inclusion of grass into the orchard can modulate soil features like water and fertility.

58

59

60

61

62

63

64

65

66

67

68

69

70

71

72

73

74

75

76

77 Sowing grass may potentially adjust the enrichment and paucity of soil water content to keep it relatively stable (Liu et al., 2013). It can reduce surface runoff and enhance infiltration, alleviating soil erosion (Fourie et al., 2007). Moreover, with the increase of grass age, soil infiltration and water holding capacity will be greatly improved (Palese et al., 2014). There is competition for water between grass and tree, which varies with plant species and the amount of rainfall. The competition can be weak under suitable species combination and system management. Inclusion of grass can also be beneficial to improve the contents of organic matter (Sánchez et al., 2007), nitrogen (N), phosphorus (P) and potassium in soils (Shui et al., 2008). For instance, some legume species may potentially improve soil $\mathrm{N}$ availability as they have strong capacity to biologically fix atmospheric N (Yang et al., 2011). Additionally, soil microbial diversity and activity also increase in the orchard after sowing grass (Whitelaw-Weckert et al., 2007), which may be helpful for the decomposition of soil organism humus (Wardle et al., 2001). Therefore under this system the competition for soil nutrient is relatively subtle due to the improvement of soil fertility by grasses and artificial fertilization. In addition, as the pattern of orchard-grass performance is continuously improved, transforming from firstly a single mode (ground cover) to the complex three-dimensional mode (combination of cover, farming and animal husbandry), the role of grass in the system is diversified. The grasses sown in the orchard may also be used as forages for feeding animals with countable amount of biomass accumulation in certain areas. So inclusion of grass into the orchard shows advantages both at ecological and economic scales. 
78

79

80

81

82

83

84

85

86

87

88

89

90

91

92

93

94

95

96

97

98

99

100

101

102

103

104

105

106

107

108

109

110

111

112

113

114

115

116

117

The inclusion of grass has broken the water and heat exchange in soil - fruit tree - air continuum and has transformed into soil - fruit tree + grass - air continuum (Bing et al., 2002). In this way, water and heat can be more fully utilized in the system, which requires a balance between the growths of tree and grass to maximum their functions in the system. However, tree shading may be a problem for the growth of grass under the tree as insufficient light causes adverse effects on grass growth and production. Generally, leaf net photosynthetic rate (Pn) may fall under shading and rapid stomatal closure occurs (Kim et al., 2016), while appropriate shading can improve water use efficiency (WUE) of plants, which varies with plant species. Delucia et al. (1998) found that the plants usually increased photosynthetic efficiency to improve light utilization by increasing leaf area under shading. With shading, leaf chlorophyll content increases and chlorophyll $\mathrm{a} / \mathrm{b}$ value decreases to improve plant photosynthetic activity (Abrams, 1987; Lambers \& Poorter, 1992). Singhakumara et al. (2003) found that the shade-tolerant plants generally had larger leaf area, higher chlorophyll content and lower leaf mass per unit area (LMA) than the shade-sensitive ones. These aforementioned traits are important measures in plant adaptation to adverse light environments (Grassi \& Bagnaresi, 2001) and thus may be helpful in selecting suitable grasses for the orchard. However, little knowledge has been achieved on how these traits of grass under the tree respond to shading in the orchard.

On the Loess Plateau of eastern Gausu, China, apple orchard is widely established as a profitable option in this arid and infertile area. There was approximately $1.02 \times 10^{5}$ ha apple orchard established in this area with apple yield of $6.7 \times 10^{8} \mathrm{~kg}$ per year. The existing orchards are mostly lightly tilled, which is unfavorable for controlling soil and water loss (Wang et al., 2015). Some traditional thoughts, i.e. grass and tree fight for water and nutrient in soils, and thus sowing grass may increase the costs of money and labour, have retarded the performance of grass sowing in the orchards of this area. Appropriate grass species are essential for the establishment of a sustainable orchard-grass system (Wang et al., 2015) but there was still rare species suitable for the system in this region. The lucerne (Medicago sativa), white clover (Trifolium repens) and cocksfoot (Dactylis glomerata) are common forage crops widely sown and used to feed domestic animals in this region. However, it was not clear how they can be better used in the orchard.

We proposed a hypothesis that tree shading would impose heavy impacts on grass species included in the orchard in some species-specific way. In this study, biomass, leaf trait, photosynthetic gas exchange and chlorophyll feature of three forages (grasses) were measured under three shading treatments in an apple orchard. The objectives were to find out: 1) how tree shading affects biomass accumulation, leaf trait, photosynthetic gas exchange and chlorophyll feature of the forages? 2) Which of the three species is more tolerant to shading in the orchard?

\section{Materials \& Methods}

\section{Plant material and experimental design}

The experiment was conducted in a 7 year-old apple orchard at Qingyang Loess Plateau Pastoral

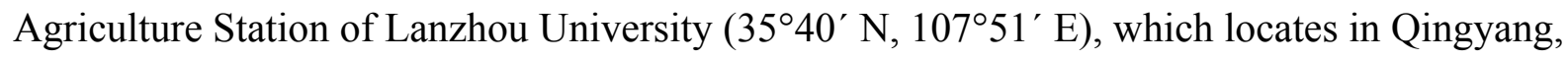
eastern Gansu of China with a typical continental climate. The mean annual precipitation is 543

Peer) reviewing PDF | (2019:05:37542:2:0:REVIEW 22 Jul 2019) 
$118 \mathrm{~mm}$ and $70 \%$ of this total usually falls in July to September. The mean annual temperature is $9.3^{\circ} \mathrm{C}$ with the lowest in January $\left(-21.3^{\circ} \mathrm{C}\right)$ and the highest in July $\left(40^{\circ} \mathrm{C}\right)$. The annual frost-free duration is $255 \mathrm{~d}$ in average. The soil is Heilu soil with $70 \%$ silt and $23 \%$ clay, representing the main cropping soil in this area.

In the intervals between tree lines ( $4 \mathrm{~m}$ wide), three forages were broadcast sown, which are lucerne (Medicago sativa), white clover (Trifolium repens) and cocksfoot (Dactylis glomerata) in July 4, 2014. The sowing rates were 22.5, 15.0 and $15.0 \mathrm{~kg} \mathrm{ha}^{-1}$ for lucerne, white clover and cocksfoot respectively. For this test, $6 \mathrm{~m}$ long ( $\times 4 \mathrm{~m}$ wide) plots were chosen and for each treatment, four replicates were set. All plots were broadcast applied with $300 \mathrm{~kg} \mathrm{ha}^{-1} \mathrm{~N}$ fertilizer in the form of urea before sowing. The forage was supposed to be cut and the shoot was removed out so that great amount of nutrient (especially $\mathrm{N}$ ) would be lost from the system, so $\mathrm{N}$ fertilizer was applied, even to legume species. Soil $\mathrm{P}$ in the orchard was excessive due to long term $\mathrm{P}$ fertilization and slow release of soil $P$ source. And the inclusion of forages would benefit the release of soil residual $\mathrm{P}$ in the orchard. So $\mathrm{P}$ fertilizer was not applied. No irrigation and pesticide spraying were performed. All the forages were cut to feed domestic animals after plant samples taken. Notably, no treatment and measurement were conducted in the first year in order to favour the establishment of grasslands under the trees.

The shading treatments were started in April 12 before the forages were reviving in the second year. Three shading treatments were set as reduced shading (partially cutting branches), normal shading (normal tree shading) and enhanced shading (normal tree shading plus sunshading net), and these treatments made the light intensity equal to about $70 \%-80 \%, 40 \%-50 \%$ and $10 \%-20 \%$ photosynthetically active radiation (PAR) above the canopy, which we measured every 2 weeks on sunny days using a portable photosynthesis system (LI-6400, Li-Cor, USA). All measurements were conducted at about two months later after shading treatment when lucerne and white clover were at early flowering stage and cocksfoot was at late heading stage. Due to budgetary limit, all measurement was only conducted in this year. Considering all three species are perennials and the second year is very close to the stabilized ages of artificial grassland in this area, the data we obtained should show the characteristics of the second year's forages.

\section{Measurements and calculations}

At least 20 youngest fully expanded leaves were sampled for each treatment. The sampled leaves were then brought back to laboratory as soon as possible for further measurements. Leaf biomass at saturated moisture content and dry weight were measured to determine leaf dry matter content (LDMC) (Garnier et al., 2001) using the equation: LDMC $\left(\mathrm{mg} \mathrm{g}^{-1}\right)=$ leaf dry weight / leaf saturated fresh biomass. Fresh leaf area $\left(\mathrm{cm}^{2}\right)$ was scanned with Win FOLIA (LA2400, Canada) and the LMA was determined using the equation: LMA $\left(\mathrm{g} \mathrm{m}^{-2}\right)=$ leaf dry weight / leaf area. In addition, leaf thickness (LT) was measured with a vernier caliper. Biomass was measured with drying method. After sampling with quadrat frame of $1 \mathrm{~m} \times 1 \mathrm{~m}$, the samples were dried at $80^{\circ} \mathrm{C}$ until constant weight and measured the biomass on the ground. 
158

159

160

161

162

163

164

165

166

167

168

169

170

171

172

173

174

175

176

177

178

179

180

181

182

183

184

185

186

187

188

189

190

191

192

193

194

195

196

197

Constant photosynthetic gas exchange was measured with a portable photosynthesis system (LI-6400, Li-Cor, USA) at 9:30 - 11:30 am on a clear sunny day during leaf sampling. The $\mathrm{CO}_{2}$ concentration was maintained at $400 \mu \mathrm{L} \mathrm{L}^{-1}$ using $\mathrm{CO}_{2}$ supplying cartridge. The $\mathrm{Pn}\left(\mu \mathrm{mol} \mathrm{m}^{-2} \mathrm{~s}^{-}\right.$ ${ }^{1}$ ) and transpiration rate $\left(\mathrm{E}, \mathrm{mmol} \mathrm{m}^{-2} \mathrm{~s}^{-1}\right.$ ) were recorded and instantaneous WUE (WUEi, $\mu \mathrm{mol}$ $\mathrm{mmol}^{-1}$ ) was calculated as $\mathrm{Pn} / \mathrm{E}$. In each replicate, three plants were selected randomly and at least three healthy and fully expanded leaves were measured. The Pn response to light gradient was measured at 09:00-11:00 on a clear sunny day using the red and blue light source equipped with LI-6400. During the measurements, $\mathrm{CO}_{2}$ concentration was maintained at $400 \mu \mathrm{L} \mathrm{L}^{-1}$ using $\mathrm{CO}_{2}$ supplying cartridge and light intensity was set according to the Equipment Instruction. The curve was then fit with the classic Farquhar model (Farquhar et al., 2001) to obtain light compensation point (LCP), light saturation point (LSP), dark respiration rate (Rd), maximum assimilation rate (Amax) and apparent quantum efficiency (Qapp).

Chlorophyll $\mathrm{a}$ and $\mathrm{b}$ was extracted by mixture of propanone and anhydrous ethyl alcohol, and then the contents were determined by spectrophotometer method of Arnon (1949). The contents of chlorophyll $\mathrm{a}, \mathrm{b}$ and $\mathrm{a}+\mathrm{b}$ were calculated using the following equations:

Chlorophyll a $\left(\mathrm{mg} \mathrm{g}^{-1}\right)=[(12.7 \times \mathrm{A} 663-2.59 \times \mathrm{A} 645) \mathrm{V} / \mathrm{W}]$,

Chlorophyll b $\left(\mathrm{mg} \mathrm{g}^{-1}\right)=[(22.9 \times \mathrm{A} 645-4.67 \times \mathrm{A663}) \mathrm{V} / \mathrm{W}]$,

Chlorophyll a+b $\left(\mathrm{mg} \mathrm{g}^{-1}\right)=[(20.3 \times \mathrm{A} 645+8.04 \times \mathrm{A663}) \mathrm{V} / \mathrm{W}]$,

Where $\mathrm{A}$ is absorbance at specific wavelengths; $\mathrm{V}$ is final volume of chlorophyll extract; $\mathrm{W}$ is fresh weight of leaf extracted. In the present experiment, the volume (V) and weight (W) were $100 \mathrm{ml}$ and $0.1 \mathrm{~g}$, respectively.

Chlorophyll fluorescence was measured at 09:00-11:00 on a clear sunny day to obtain actual photochemical efficiency of photosystem II ( $\phi$ PS II), photochemical quenching coefficient (qP) and non-photochemical quenching (NPQ) using fluorescent leaf chamber of LI-6400 with controlled light intensity of $1500 \mu \mathrm{mol} \mathrm{m}^{-2} \mathrm{~s}^{-1}$. Prior to these measurements, marked leaves were measured in dark to determine maximum photochemical rate $(\mathrm{Fv} / \mathrm{Fm})$ at 01:00 deep night. In each replicate, three plants were selected randomly and at least three healthy and fully expanded leaves were measured.

\section{Data analysis}

The effects of shading treatment, forage species and their interaction on leaf trait, gas exchange, chlorophyll component and fluorescence were analyzed using factor analysis. The differences in leaf traits, gas exchange parameters and chlorophyll features among forages or shading treatments were analyzed using Two-Way ANOVA. The Pn-PAR curve was fit with the classic Farquhar model to gain related parameters. Correlations among the growth and leaf photosynthetic characteristics of three forages under shading were analyzed using Spearman's rank correlation analysis. The SPSS 17.0 was used for statistical analysis.

\section{Results}

\section{Leaf traits and biomass growth under shading}


198 The LDMC and LMA of three forages were affected by shading, species and their interaction,

199

200

201

202

203

204

205

206

207

208

209

210

211

212

213

214

215

216

217

218

219

220

221

222

223

224

225

226

227

228

229

230

231

232

233

234

235

236

237

while the LT was only affected by shading and the biomass was only affected by species (Table 1). The LT of cocksfoot did not change under all treatments but it tended to decrease with the enhancement of shading. The LT of white clover decreased with the enhancement of shading. For lucerne, LT was reduced by enhanced shading and did not change under reduced shading (Fig. 1A). The LDMC of cocksfoot and lucerne decreased with the enhancement of shading. For white clover, LDMC was reduced by enhanced shading and was not changed by reduced shading (Fig. 1B). The LMA of all three forages decreased with the enhancement of shading (Fig. 1C). In response to the enhancement of shading, LT of cocksfoot did not change, but LDMC and LMA decreased, and its LMA was the lowest among all forages under enhanced shading (Fig. 1). The biomass of cocksfoot was much higher than the other forages, which tended to decrease with enhanced shading. The biomass of white clover and lucerne were not changed by shading (Fig. 1D).

\section{Leaf photosynthetic gas exchange under shading}

The Pn and WUEi were affected by shading, species and their interaction (Table 1). The Pn of cocksfoot was reduced by enhanced shading and did not change under reduced shading. The Pn of white clover and lucerne decreased with the enhancement of shading (Fig. 2A). The WUEi of cocksfoot decreased with the enhancement of shading. For whiter clover and lucerne, WUEi was elevated by enhanced and reduced shading (Fig. 2B). In response to the enhancement of shading, the Pn of cocksfoot changed little and both Pn and WUEi were not different from those of other two forages under enhanced shading (Fig. 2).

The shading imposed various impacts on Pn-PAR curves of different forages (Table 2).The $\mathrm{Rd}$ of cocksfoot was elevated by reduced shading but was not impacted by enhanced shading. The Amax and LCP of cocksfoot tended to decrease with the enhancement of shading, while LSP was reduced by enhanced and reduced shading but Qapp was elevated. The Rd of white clover was reduced by enhanced and reduced shading. The Amax, LCP and LSP of white clover tended to decrease with the enhancement of shading. Its Qapp tended to decrease under enhanced and reduced shading. For lucerne, the Rd, Amax and LCP tended to decrease with the enhancement of shading. The LSP tended to decrease under enhanced and reduced shading but the Qapp was elevated. The Rd and LCP of cocksfoot were lower than other forages but the Amax was not different and the Qapp was even higher under enhanced shading.

\section{Leaf chlorophyll component and fluorescence under shading}

The content and proportion of chlorophyll component were affected by species, but seldom by shading and their interaction (Table 1). For cocksfoot, the contents of all chlorophyll components and chlorophyll a/b were not impacted by enhanced and reduced shading (Fig. 3). For white clover, the contents of chlorophyll $\mathrm{a}, \mathrm{b}$ and $\mathrm{a}+\mathrm{b}$ increased with the enhancement of shading, while chlorophyll $\mathrm{a} / \mathrm{b}$ decreased. For lucerne, the contents of all chlorophyll components and chlorophyll a/b were not changed by enhanced and reduced shading (Fig. 3). The contents of

Peer) reviewing PDF | (2019:05:37542:2:0:REVIEW 22 Jul 2019) 
238

239

240

241

242

243

244

245

246

247

248

249

250

251

252

253

254

255

256

257

258

259

260

261

262

263

264

265

266

267

268

269

270

271

272

273

274

275

276

277

chlorophyll $\mathrm{a}, \mathrm{b}$ and $\mathrm{a}+\mathrm{b}$ were highest in cocksfoot, while for chlorophyll $\mathrm{a} / \mathrm{b}$, it appeared as white clover $>$ lucerne> cocksfoot (Fig. 3).

Chlorophyll fluorescence was affected by species and their interaction (Table 1). The Fv/Fm increased with the enhancement of shading in cocksfoot and was not changed in white clover, while in lucerne, $\mathrm{Fv} / \mathrm{Fm}$ was elevated by enhanced and reduced shading, and it was higher under reduced shading than enhanced shading (Fig. 4A). The $\phi P S$ II and qP of cocksfoot were lowered by enhanced and reduced shading and in white clover they were not impacted, while in lucerne, the $\phi$ PS II and qP decreased with the enhancement of shading (Fig. 4B and 4C). In cocksfoot, the $\phi P S$ II and qP were higher under enhanced shading than reduced shading. The NPQ of cocksfoot decreased with the enhancement of shading. For white clover, NPQ was lowered by enhanced and reduced shading, while in lucerne, NPQ was elevated (Fig. 4D). In response to the enhancement of shading, the Fv/Fm increased in cocksfoot and its NPQ was far lower than those in other two forages (Fig. 4A and 4D).

\section{Correlations among the growth and leaf photosynthetic characteristics of three forages under shading}

The biomass was positively correlated with WUEi, chlorophyll $\mathrm{a}, \mathrm{b}$ and $\mathrm{a}+\mathrm{b}$ contents, but negatively correlated with chlorophyll a/b, Fv/Fm, $\phi$ PS II, qP and NPQ (Table 3). The Pn was positively correlated with LDMC, LMA, chlorophyll a/b, Fv/Fm, $\phi \mathrm{PS}$ II and qP, but negatively correlated with chlorophyll $\mathrm{a}+\mathrm{b}$ content. The WUEi was positively correlated with LDMC, LMA, chlorophyll $\mathrm{a}, \mathrm{b}$ and $\mathrm{a}+\mathrm{b}$ contents, but negatively correlated with chlorophyll a/b, Fv/Fm, $\phi$ PS II, $\mathrm{qP}$ and NPQ.

\section{Discussion}

\section{Effects of shading on leaf traits of three forages}

Leaf trait is partly the consequence that a plant responds to the external environments at leaf scale (Vendramini et al., 2002) and its change is one of the most important strategies that the plant has developed to cope with adverse environments. This study showed that species, shading and their interaction imposed significant impacts on leaf traits. Shading reduced LT, LDMC and LMA. Thus, shading may reduce assimilates accumulation but enhance the allocation for potential enhancement of photosynthetic photon capture because lower LT, LDMC and LMA generally indicate more input into photosynthetic area (Modrzy et al., 2015).These changes would result in enhanced photosynthesis. In addition, shading may help to maintain soil water status and improve air humidity under the tree, which potentially ameliorate the possible water stress that the forages are encountering, especially in this semi-arid and rainfed region. The LT wasn't affected by species, but it tended to be higher in cocksfoot than other species and did not change with shading, suggesting that cocksfoot may be more tolerant to shading. Much quicker decline in LMA of cocksfoot also proved that this species is more adaptive to shading, as lower LMA shows stronger potential to use weak light under the tree. 
278 Effects of shading on chlorophyll contents and fluorescence of three forages

279 Generally, a plant with high chlorophyll content and low chlorophyll a/b has stronger resistance

280 to shading (Boardman, 1977). In this study, species and its interaction with shading significantly 281 affected chlorophyll $\mathrm{a}, \mathrm{b}, \mathrm{a}+\mathrm{b}$ contents and $\mathrm{a} / \mathrm{b}$, while shading showed rare effect. Only in white 282 clover, the contents reduced and chlorophyll $\mathrm{a} / \mathrm{b}$ increased along with the reduction in shading, 283 suggesting that chlorophyll content and ratio weren't influenced by shading in cocksfoot and 284 lucerne. Intriguingly, the contents of chlorophyll component in cocksfoot were highest, but 285 chlorophyll a/b was lowest, indicating that cocksfoot is more efficient in use of weak light 286 because high chlorophyll b content and proportion promise a plant to do so (Abrams, 1987; 287 Threlfall, 1981).

288

289

290

291

292

293

294

295

296

297

298

299

300

301

302

303

304

305

306

307

308

309

310

311

312

313

314

315

316

317

Chlorophyll fluorescence reflects the actual and maximum photosynthesis, the function of reaction center and the heat dissipation of a plant (Govindjee, 2002). In this study, all fluorescence was significantly affected only by species. The NPQ tended to be lowest in cocksfoot, and the Fv/Fm increased with the enhancement of shading, suggesting that this species is more tolerant to shading. The increased $\mathrm{Fv} / \mathrm{Fm}$ reflects the enhancement of potential PSII photochemical efficiency of leaves after a fully dark adaptation (Demmig \& Björkman, 1987). The lower NPQ shows less light energy consumption as heat dissipation (Genty et al., 1989). Compared to lucerne and white clover, cocksfoot showed normal light conversing efficiency and light trapping efficiency under shading, but much lower light energy loss, helping to adapt to weakened light environments.

\section{Effects of shading on Pn, WUEi and biomass of three forages}

In this study, constant Pn and WUEi were significantly affected by species, shading and their interaction. The Pn and WUEi tended to decrease with the enhancement of shading. These may suggest that under tree shading, weakened light led to Pn decrease because generally, Pn and light intensity are positively correlated with suitable water supply under natural light. However, improved water status in soils and relative air humidity under the trees would have kept stomata open, consequently leading to great transpiration (rate). Thus, the WUEi would decrease with shading as it was calculated with Pn/E. From another viewpoint, it also proved that shading may improve water supply around the forage and tree. Changes in Pn with shading among species may be due to variations in leaf traits and chlorophyll features as there were positive correlations of Pn with LDMC, LMA and chlorophyll $\mathrm{a} / \mathrm{b}$, $\phi$ PS II and $\mathrm{qP}$, and negative correlation with chlorophyll $\mathrm{a}+\mathrm{b}$ content. As for WUEi, there were contrasting roles played by chlorophyll features as the WUEi was positively correlated with chlorophyll $\mathrm{a}, \mathrm{b}$ and $\mathrm{a}+\mathrm{b}$ contents, but negatively correlated with chlorophyll a/b, Fv/Fm, $\phi P S$ II, qP and NPQ. Compared with other forages, the Pn of cocksfoot changed little with shading, and both Pn and WUEi were not different from other forages, suggesting that this species was more tolerant to shading.

The Pn-PAR curve provides very useful parameters to address photosynthetic responses of a plant to adverse environment, while eliminating much interference, i.e. insufficient light radiation (Lewis et al., 2000). In this study, the LCP and Amax decreased with the enhancement

Peer) reviewing PDF | (2019:05:37542:2:0:REVIEW 22 Jul 2019) 
318 of shading, suggesting that all species are acclimating to shading, while the Rd, Qapp and LSP 319 changed in a species-specific way. Compared to white clover and lucerne, the Rd and LCP of 320 cocksfoot were lower, but the Amax was similar, and the Qapp was even higher under shading, 321 indicating that cocksfoot may be more tolerant. The lower LCP indicates that the plant can 322 survive in weakened light environments (Taiz \& Zeiger, 2010), i.e. tree shading, and generally, 323 shading-tolerant plants have lower Rd (Lewis et al., 2000). The greater Qapp reflects stronger

324

325

326

327

328

329

330

331

332

333

334

335

336

337

338

339

340

341

342

343

344

345

346

347

348

349

350

351

352

353

354

355

photosynthesis to use weak light. Thus, it suggested that cocksfoot could make better use of weak light and adapt to shading, compared to other species.

The biomass of cocksfoot was much higher than the other forages, which decreased little under enhanced shading compared to normal shading. Cocksfoot has good adaptability to various environmental conditions, such as drought and restricted light conditions, with good regrowth characteristics (Sanada et al., 2010). Change in biomass accumulation with shading among species was more correlated with WUEi, but not Pn in the orchard environment. Therefore, cocksfoot might be more beneficial to provide biomass under tree shading.

As known, plant biomass accumulation was not only impacted by light, but also by soil carbon and nutrients. Soil nutrients (such as $\mathrm{N}$ and $\mathrm{P}$ ) can indirectly affect the utilization of light radiation by regulating photosynthesis apparatus (Arain et al., 2002; Palmroth et al., 2014). In this study, there were similar basic soil feature and relative enough nutrient supply to soils. Therefore, the difference in effects of soil nutrients on the plant might be negligible. However, it is obliged to admit the fact soil nutrient availability would change after longer time forage growth and this would affect the response of forage to light radiation, so further studies would be required in the future.

\section{Conclusions}

Shading imposed significant impacts on the growth and leaf photosynthetic characteristics, while there were differences among species. Shading affected chlorophyll content and fluorescence, LDMC and LMA, which finally changed biomass accumulation. Cocksfoot was more efficient than the other two forages in use of weak light and more tolerant to tree shading. In the apple orchard, we recommend that selecting some shading-tolerant grasses, i.e. cocksfoot, or widening the distance between individual apple trees, would be practical options for the orchard-forage system in the Loess Plateau of China.

\section{Acknowledgements}

We appreciate very much the assistance from Mr. Binghong Duan, Ms. Yaya Wang, Dr. Qian Yang and Mr. Juncheng Li in the field work and in the lab measurement and the comments on revising this draft from Prof. Yuying Shen and Dr. Ran Xue.

\section{References}


356

357

358

359

360

361

362

363

364

365

366

367

368

369

370

371

372

373

374

375

376

377

378

379

380

381

382

383

384

385

386

387

388

389

390

391

392

393

394

395

Abrams MD. 1987. Leaf structural and photosynthetic pigment characteristics of three galleryforest hardwood species in northeast Kansas. Forest Ecology and Management 22(3-4):261266 DOI 10.1016/0378-1127(87)90110-1.

Arain MA, Black TA, Barr AG, Jarvis PG, Massheder JM, Verseghy DL, Nesic Z. 2002. Effects of seasonal and interannual climate variability on net ecosystem productivity of boreal deciduous and conifer forests. Canadian Journal of Forest Research 32(5): 878-891 DOI 10.1139/x01-228.

Arnon DI. 1949. Copper enzymes in isolated chloroplasts. Polyphenoloxidase in Beta vulgaris. Plant Physiology 24(1):1-15 DOI 10.1104/pp.24.1.1.

Boardman NK. 1977. Comparative photosynthesis of sun and shade plants. Annual Review of Plant Physiology 28(1): 355-377 DOI 10.1016/0378-1127(87)90110-1.

Bing W, Liu SR, Cui XH, Bai XL. 2002. Advances in the research on water and heat balance laws of the global terrestrial ecosystem. World Forest Research 15(1):19-28 DOI 10.1007/s11769-002-0026-8.

Delucia E, Sipe T, Herrick J, Maherali H. 1998. Sapling biomass allocation and growth in the understory of a deciduous hardwood forest. American Journal of Botany 85:955-955 DOI $10.2307 / 2446362$.

Demmig B, Björkman O. 1987. Comparison of the effect of excessive light on chlorophyll fluorescence $(77 \mathrm{~K})$ and photon yield of $\mathrm{O}_{2}$ evolution in leaves of higher plants. Planta 171(2):171-184 DOI 10.1007/BF00391092.

Farquhar GD, Caemmerer SV, Berry JA. 2001. Models of photosynthesis. Plant Physiology 125(1):42-45 DOI 10.1104/pp.125.1.42.

Fourie JC, Louw PJE, Agenbag GA. 2007. Cover crop management in a Sauvignon blanc/Ramsey vineyard in the semi-arid Olifants River Valley, South Africa. 2. Effect of different cover crops and cover crop management practices on grapevine performance. South African Journal of Enology and Viticulture 28(2):81-91 DOI 10.3166/sda.27.455-470.

Garnier E, Shipley B, Roumet C, Laurent G. 2001. A standardized protocol for the determination of specific leaf area and leaf dry matter content. Functional Ecology 15(5) (5):688-695 DOI 10.1046/j.0269-8463.2001.00563.x.

Genty B, Briantais JM, Baker NR. 1989. The relationship between the quantum yield of photosynthetic electron transport and quenching of chlorophyll fluorescence. Biochimica et Biophysica Acta (BBA)-General Subjects 990(1):87-92

DOI 10.1016/S0304-4165(89)80016-9.

Govindjee. 2002. A role for a light-harvesting antenna complex of photosystem II in photoprotection. The Plant Cell 14(8):1663-1668 DOI 10.1105/tpc.140810.

Grassi G, Bagnaresi U. 2001. Foliar morphological and physiological plasticity in Picea abies and Abies alba saplings along a natural light gradient. Tree Physiology 21(12-13):959-967 DOI 10.1093/treephys/21.12-13.959.

Kim D, Oren R, Qian SS. 2016. Response to $\mathrm{CO}_{2}$ enrichment of understory vegetation in the shade of forests. Global Change Biology 22(2):944-956 DOI 10.1111/gcb.13126. 
396

397

398

399

400

401

402

403

404

405

406

407

408

409

410

411

412

413

414

415

416

417

418

419

420

421

422

423

424

425

426

427

428

429

430

431

432

433

434

Lambers H, Poorter H. 1992. Inherent variation in growth rate between higher plants: a search for physiological causes and ecological consequences. Advances in Ecological Research 22(1):187-261 DOI 10.1016/S0065-2504(08)60148-8.

Lewis JD, McKane RB, Tingey DT, Beedlow PA. 2000. Vertical gradients in photosynthetic light response within an old-growth Douglas-fir and western hemlock canopy. Tree Physiology 20(7):447-456 DOI 10.1093/treephys/20.7.447.

Liu Y, Gao M, Wu W, Tanveer SK, Wen X, Liao Y. 2013. The effects of conservation tillage practices on the soil water-holding capacity of a non-irrigated apple orchard in the Loess Plateau, China. Soil and Tillage Research 130:7-12 DOI 10.1016/j.still.2013.01.012.

Modrzy JS, Chmura JD, Tjoelker GM, Thomas S. 2015. Seedling growth and biomass allocation in relation to leaf habit and shade tolerance among 10 temperate tree species. Tree Physiology 35(8):879-893 DOI 10.1093/treephys/tpv053.

Monteiro A, Lopes CM. 2007. Influence of cover crop on water use and performance of vineyard in Mediterranean Portugal. Agriculture, ecosystems \& environment 121(4):336-342 DOI 10.1016/j.agee.2006.11.016.

Neves CSVJ, Tavares-Filho J, Brito OR Yamashita F, Tormem V, de Batista Fonseca IC. 2010. Citrus orchard planted with no tillage and conventional systems. Semina: Ciências Agrárias (Londrina) 31:1263-1273 DOI 10.5433/1679-0359.2010v31n4Sup1p1263.

Palmroth S, Holm Bach L, Nordin A, Palmqvist K. 2014. Nitrogen-addition effects on leaf traits and photosynthetic carbon gain of boreal forest understory shrubs. Oecologia 175(2): 457-470 DOI 10.1007/s00442-014-2923-9.

Palese AM, Vignozzi N, Celano G, Agnelli AE, Pagliai M, Xiloyannis C. 2014. Influence of soil management on soil physical characteristics and water storage in a mature rainfed olive orchard. Soil and Tillage Research 144: 96-109 DOI 10.1016/j.still.2014.07.010.

Sanada Y, Gras MC, Santen EV. 2010. Cocksfoot. Fodder Crops and Amenity Grasses Springer New York. DOI 10.1007/978-1-4419-0760-8_13.

Sánchez EE, Giayetto A, Cichón L, Fernández D, Aruani MC, Curetti M. 2007. Cover crops influence soil properties and tree performance in an organic apple (Malus domestica Borkh) orchard in northern Patagonia. Plant and Soil 292(1-2):193-203

DOI 10.1007/s11104-007-9215-7.

Shui JG, Wang QZ, Liao GQ, Au J, Allard JL. 2008. Ecological and economic benefits of vegetation management measures in citrus orchards on red soils. Pedosphere 18(2):214-221 DOI 10.1016/s1002-0160(08)60009-0.

Singhakumara BMP, Gamage HK, Ashton MS. 2003. Comparative growth of four Syzygium species within simulated shade environments of a Sri Lankan rain forest. Forest Ecology and Management 174(1-3):511-520 DOI 10.1016/s0378-1127(02)00071-3.

Skroch WA, Shribbs JM. 1986. Orchard floor management: an overview. HortScience 21(3):390-394 DOI 10.1079/9781845933869.0332.

Taiz L, Zeiger E. 2010. Plant physiology, 5th edn. Sinauer Associates Inc, Sunderland, MA. 
435

436

437

438

439

440

441

442

443

444

445

446

447

448

449

450

451

452

453

454

455

456

457

Teravest D, Smith JL, Carpenter-Boggs L, Hoagland L, Granatstein D, Reganold JP. 2010. Influence of orchard floor management and compost application timing on nitrogen partitioning in apple trees. HortScience, 45(4):637-642 DOI 10.1590/S0102-05362010000200019.

Threlfall DR. 1981. The biochemistry of the carotenoids, volume I, plants: TW Goodwin, Chapman \& Hall, London, 1980. 377. Phytochemistry 20:2449-2450 DOI 10.1016/S0031-9422(00)82696-5.

Vendramini F, Díaz S, Gurvich DE, Wilson PJ, Thompson K, Hodgson JG. 2002. Leaf traits as indicators of resource-use strategy in floras with succulent species. New Phytologist 154(1):147-157 DOI 10.1046/j.1469-8137.2002.00357.x.

Wang YT, Ji XH, Wu YS, Mao ZQ, Jiang YM, Peng FT, Chen XS. 2015. Research progress of cover crop in Chinese orchard. Chinese Journal of Applied Ecology 26(6):1892-1900 DOI 10.1086/323356.

Wardle DA, Yeates GW, Bonner KI, Nicholson KS, Watson RN. 2001. Impacts of ground vegetation management strategies in a kiwifruit orchard on the composition and functioning of the soil biota. Soil Biology and Biochemistry 33(7-8):893-905

DOI 10.1016/S0038 0717(00)00235-2.

Whitelaw-Weckert MA, Rahman L, Hutton RJ, Coombes N. 2007. Permanent swards increase soil microbial counts in two Australian vineyards. Applied Soil Ecology 36(23):224-232 DOI 10.1016/j.apsoil.2007.03.003.

Yang HM, He SB, Shen YY, Wang XZ. 2011. Soil nitrogen, carbon and phosphorus after lucerne conversion to wheat or fallow in the Loess Plateau of China. Philippine journal of crop science 36(3):28-33 DOI 10.1002/jpln.201100148. 


\section{Table $\mathbf{1}$ (on next page)}

Effects of species, shading and their interaction on leaf trait, photosynthetic gas exchange and chlorophyll feature in the orchard-forage system.

NS indicates non-significant; * indicates significance at $P \leq 0.05$; ** indicates significance at $P$ $\leq 0.01 ; * * *$ indicates significance at $P \leq 0.001$. LT, leaf thickness; LDMC, leaf dry matter content; LMA, leaf mass per unit area; $\mathrm{Pn}$, net photosynthetic rate; $\mathrm{WUE}_{\mathrm{i}}$, instantaneous water use efficiency; Fv/Fm, maximum photochemical rate; $\phi P S ~ I I$, actual photochemical efficiency of PS II; qP, photochemical quenching coefficient; NPQ, non-photochemical quenching. 


\begin{tabular}{|c|c|c|c|c|c|c|c|c|c|c|c|c|c|c|}
\hline \multirow{3}{*}{ Factor } & \multirow{3}{*}{ Biomass } & \multirow{3}{*}{ LT } & \multirow{3}{*}{ LDMC } & \multirow{3}{*}{ LMA } & \multirow{3}{*}{ Pn } & \multirow{3}{*}{ WUE $_{i}$} & \multirow{3}{*}{$\begin{array}{l}\text { Chlorophyll } \\
\qquad \begin{array}{l}a\end{array}\end{array}$} & \multirow{3}{*}{$\begin{array}{c}\text { Chlorophyll } \\
\text { b }\end{array}$} & \multirow{3}{*}{$\begin{array}{l}\text { Chlorophyll } \\
\qquad a+b\end{array}$} & \multirow{3}{*}{$\begin{array}{c}\text { Chlorophyll } \\
\qquad a / b\end{array}$} & \multirow{3}{*}{$\mathrm{Fv} / \mathrm{Fm}$} & \multirow{3}{*}{$\phi \mathrm{PS}$ II } & \multirow{3}{*}{$q \mathrm{P}$} & \multirow{3}{*}{ NPQ } \\
\hline & & & & & & & & & & & & & & \\
\hline & & & & & & & & & & & & & & \\
\hline Species & $* * *$ & NS & $* * *$ & $* *$ & $* *$ & $* * *$ & $* * *$ & $* * *$ & $* * *$ & $* * *$ & $* * *$ & $* * *$ & $* * *$ & $* * *$ \\
\hline Shading & NS & $*$ & $* * *$ & $* * *$ & $* * *$ & $* * *$ & NS & NS & NS & $*$ & NS & NS & NS & NS \\
\hline Species $\times$ Shading & NS & NS & $*$ & $* * *$ & $* * *$ & $* * *$ & $*$ & NS & $*$ & NS & $* *$ & $* *$ & $* *$ & $* *$ \\
\hline
\end{tabular}

1 


\section{Table 2 (on next page)}

Optimized parameters of the exponential rise to max function from Pn-PAR curves of three forages under shading.

$\mathrm{Rd}$, dark respiration rate; Qapp, apparent quantum efficiency; LCP, light compensation point; LSP, light saturation point. Amax, maximum assimilation rate. 


\begin{tabular}{|c|c|c|c|c|c|c|c|c|c|}
\hline & \multicolumn{3}{|c|}{ Cocksfoot } & \multicolumn{3}{|c|}{ White clover } & \multicolumn{3}{|c|}{ Lucerne } \\
\hline & $\begin{array}{c}\text { Enhanced } \\
\text { shading }\end{array}$ & $\begin{array}{l}\text { Normal } \\
\text { shading }\end{array}$ & $\begin{array}{l}\text { Reduced } \\
\text { shading }\end{array}$ & $\begin{array}{l}\text { Enhanced } \\
\text { shading }\end{array}$ & $\begin{array}{l}\text { Normal } \\
\text { shading }\end{array}$ & $\begin{array}{l}\text { Reduced } \\
\text { shading }\end{array}$ & $\begin{array}{c}\text { Enhanced } \\
\text { shading }\end{array}$ & $\begin{array}{l}\text { Normal } \\
\text { shading }\end{array}$ & $\begin{array}{l}\text { Reduced } \\
\text { shading }\end{array}$ \\
\hline $\operatorname{Rd}\left(\mu \mathrm{mol} \mathrm{m} \mathrm{m}^{-2} \mathrm{~s}^{-1}\right)$ & 0.35 & 0.33 & 1.54 & 1.22 & 1.60 & 1.29 & 1.24 & 2.21 & 3.28 \\
\hline Qapp $\left(\mu \mathrm{mol} \mathrm{mol}^{-1}\right)$ & 0.07 & 0.04 & 0.10 & 0.06 & 0.07 & 0.05 & 0.06 & 0.05 & 0.06 \\
\hline $\mathrm{LCP}\left(\mu \mathrm{mol} \mathrm{m}{ }^{-2} \mathrm{~s}^{-1}\right)$ & 5.1 & 8.3 & 15.9 & 21.3 & 24.1 & 26.7 & 21.4 & 46.8 & 58.7 \\
\hline $\operatorname{LSP}\left(\mu \mathrm{mol} \mathrm{m}{ }^{-2} \mathrm{~s}^{-1}\right)$ & 722 & 1757 & 707 & 524 & 544 & 1079 & 814 & 880 & 819 \\
\hline $\operatorname{Amax}\left(\mu \mathrm{mol} \mathrm{m}{ }^{-2} \mathrm{~s}^{-1}\right)$ & 13.8 & 17.7 & 25.3 & 13.2 & 16.4 & 19.8 & 18.2 & 20.0 & 24.5 \\
\hline
\end{tabular}




\section{Table 3 (on next page)}

Correlations among the biomass, leaf thickness (LT), leaf dry matter content (LDMC), leaf mass per unit area (LMA), net photosynthetic rate (Pn), instantaneous water use efficiency (WUEi), chlorophyll content and fluorescence of three forages under trees.

Spearman's correlation coefficients $(n=108)$ are shown. Significance are shown with $* * *$ ( $P \leq$ $0.001)$, ** $(P \leq 0.01)$ and * $(P \leq 0.05)$. Fv/Fm, maximum photochemical rate; $\phi P S I I$, actual photochemical efficiency of PS II; qP, photochemical quenching coefficient; NPQ, nonphotochemical quenching. 


\begin{tabular}{|c|c|c|c|c|c|c|c|c|c|c|c|c|c|}
\hline & LT & LDMC & LMA & Pn & WUEi & $\begin{array}{c}\text { Chlorophyll } \\
\quad a\end{array}$ & $\begin{array}{c}\text { Chlorophyll } \\
b\end{array}$ & $\begin{array}{l}\text { Chlorophyll } \\
\qquad a+b\end{array}$ & $\begin{array}{c}\text { Chlorophyll } \\
\qquad a / b\end{array}$ & $\mathrm{Fv} / \mathrm{Fm}$ & $\phi P S$ II & $\mathrm{qP}$ & NPQ \\
\hline Biomass & 0.06 & 0.14 & 0.04 & -0.15 & $0.49^{* * *}$ & $0.54 * * *$ & $0.79 * * *$ & $0.73^{* * *}$ & $-0.79 * * *$ & $-0.52 * * *$ & $-0.60 * * *$ & $-0.63 * * *$ & $-0.49 * * *$ \\
\hline Pn & 0.11 & $0.30 * *$ & $0.31 * *$ & 1 & $0.30^{* *}$ & -0.17 & -0.19 & $-0.19 *$ & $0.24^{*}$ & $0.25 * *$ & $0.29 * *$ & $0.32 * * *$ & -0.05 \\
\hline $\mathrm{WUE}_{\mathrm{i}}$ & 0.04 & $0.22 *$ & $0.38^{* * *}$ & $0.30^{* *}$ & 1 & $0.23 *$ & $0.39^{* * *}$ & $0.34 * * *$ & $-0.39^{* * *}$ & $-0.29 * *$ & $-0.32 * * *$ & $-0.33 * * *$ & $-0.31 * *$ \\
\hline
\end{tabular}


Figure 1

Leaf thickness (LT) (A), leaf dry matter content (LDMC) (B), leaf mass per unit area (LMA) (C) and biomass (D) of three forages under shading.

Different capital letters denote significant differences among species under the same shading treatment $(P \leq 0.05)$. Different lowercase letters denote significant differences among shading treatments for the same species $(P \leq 0.05)$. Bars show standard deviation.
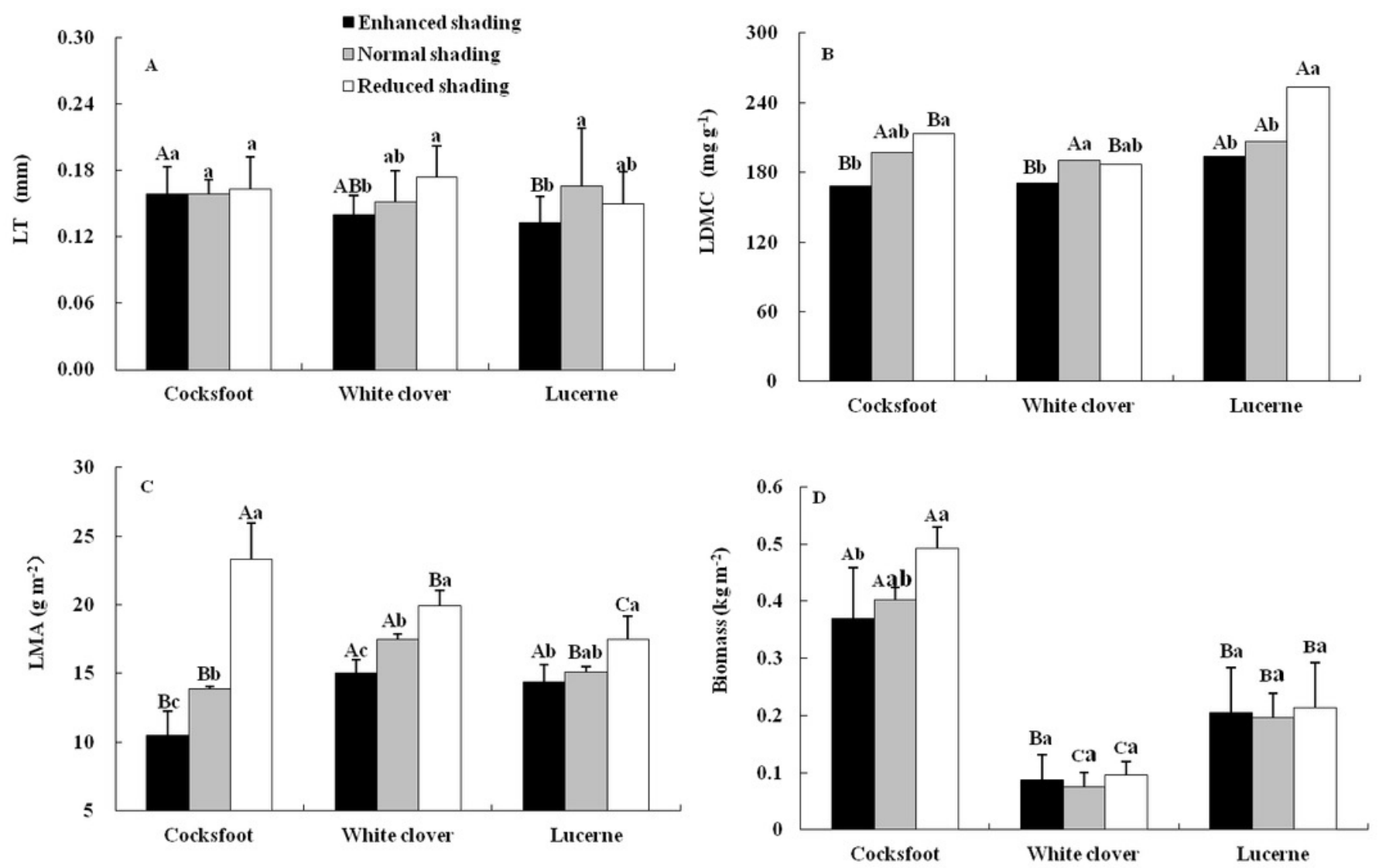


\section{Figure 2}

Net photosynthetic rate $(\mathrm{Pn})(\mathrm{A})$ and instantaneous water use efficiency (WUEi) (B) of three forages under shading.

Different capital letters denote significant differences among species under the same shading treatment $(P \leq 0.05)$. Different lowercase letters denote significant differences among shading treatments for the same species $(P \leq 0.05)$. Bars show standard deviation. 

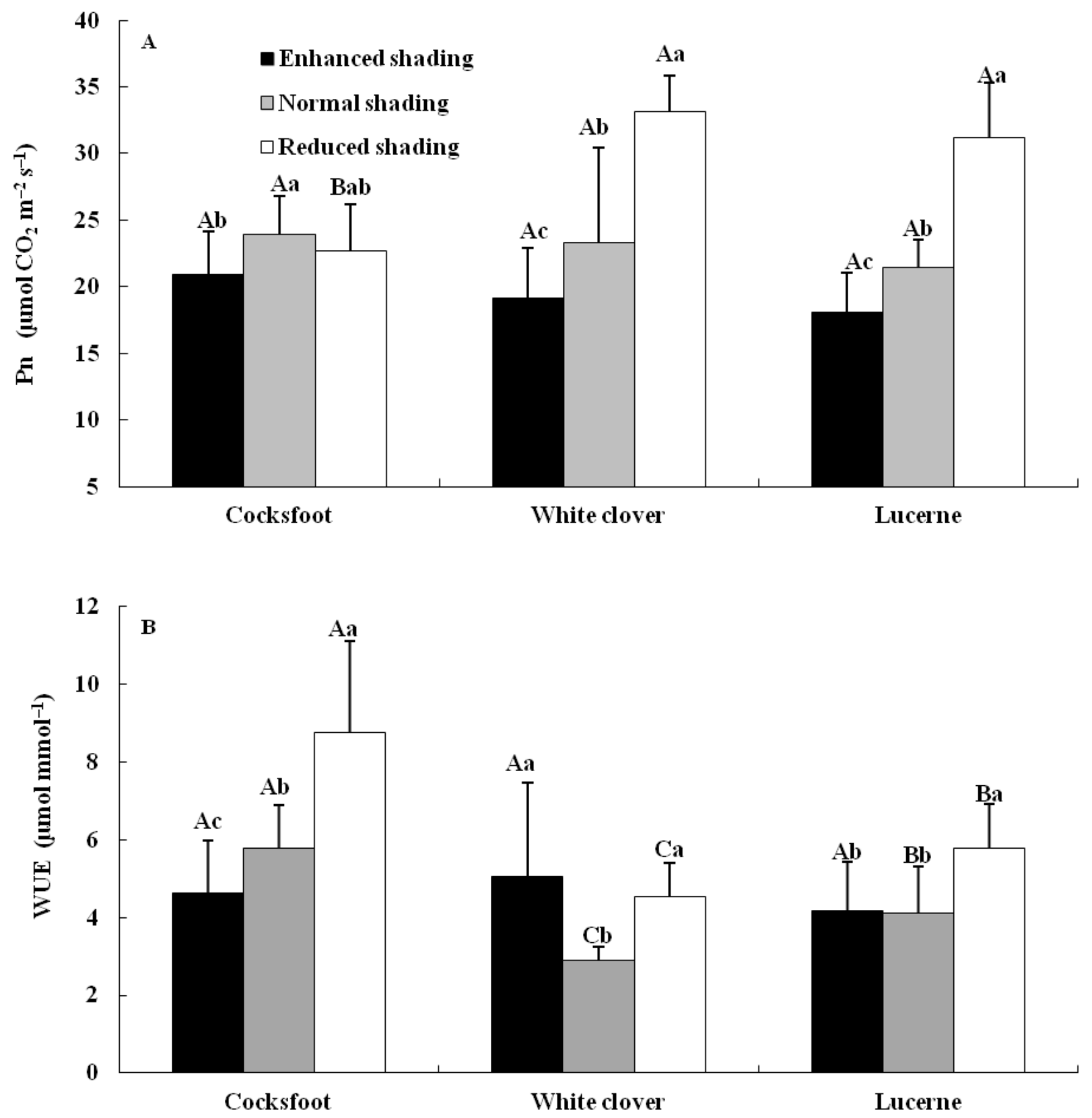


\section{Figure 3}

Chlorophyll component and content in leaves of three forages under shading.

Different capital letters denote significant differences among species under the same shading treatment $(P \leq 0.05)$. Different lowercase letters denote significant differences among shading treatments for the same species $(P \leq 0.05)$. Bars show standard deviation.
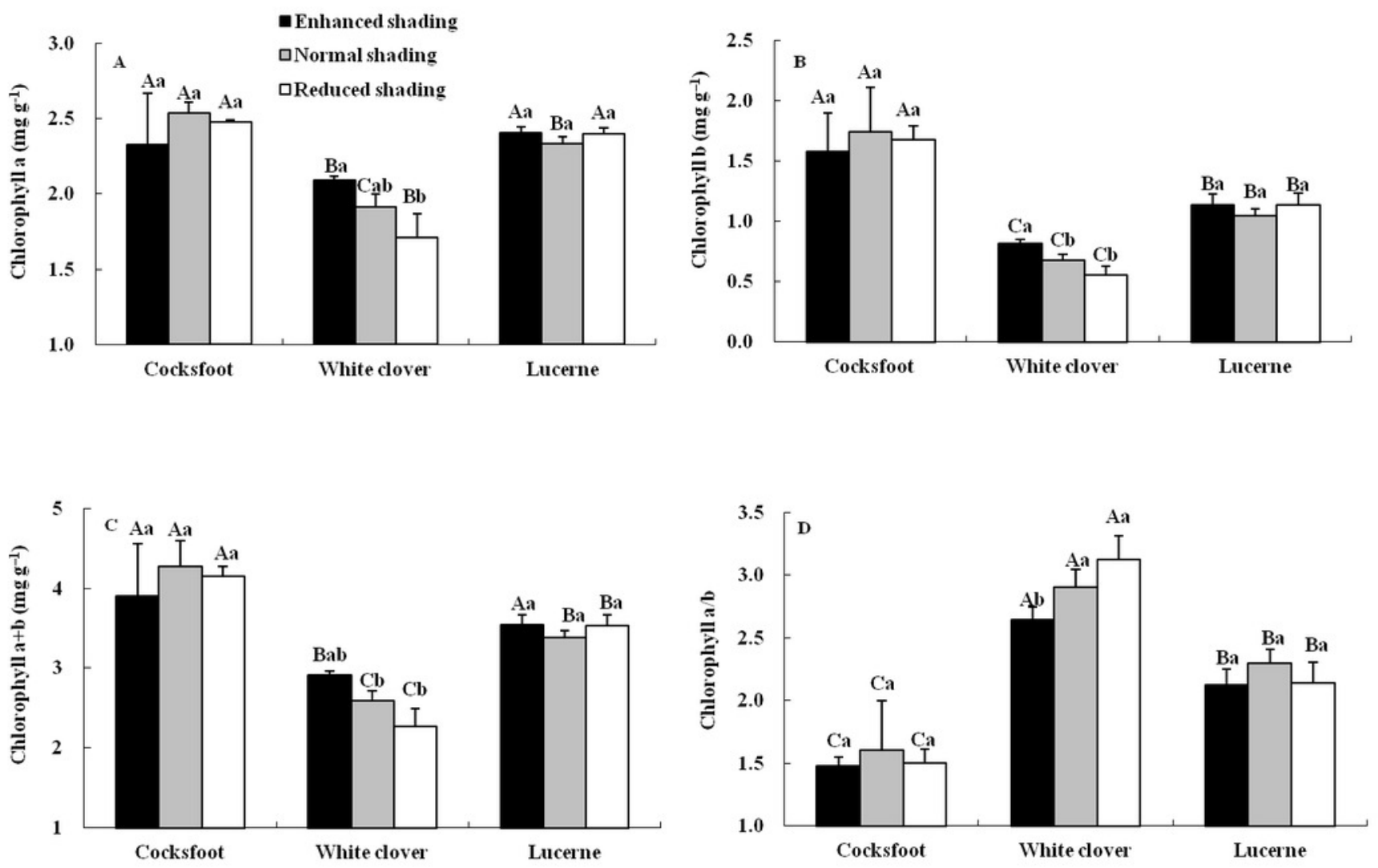


\section{Figure 4}

Chlorophyll fluorescence in leaves of three forages under shading.

Different capital letters denote significant differences among species under the same shading treatment $(P \leq 0.05)$. Different lowercase letters denote significant differences among shading treatments for the same species $(P \leq 0.05)$. Bars show standard deviation.
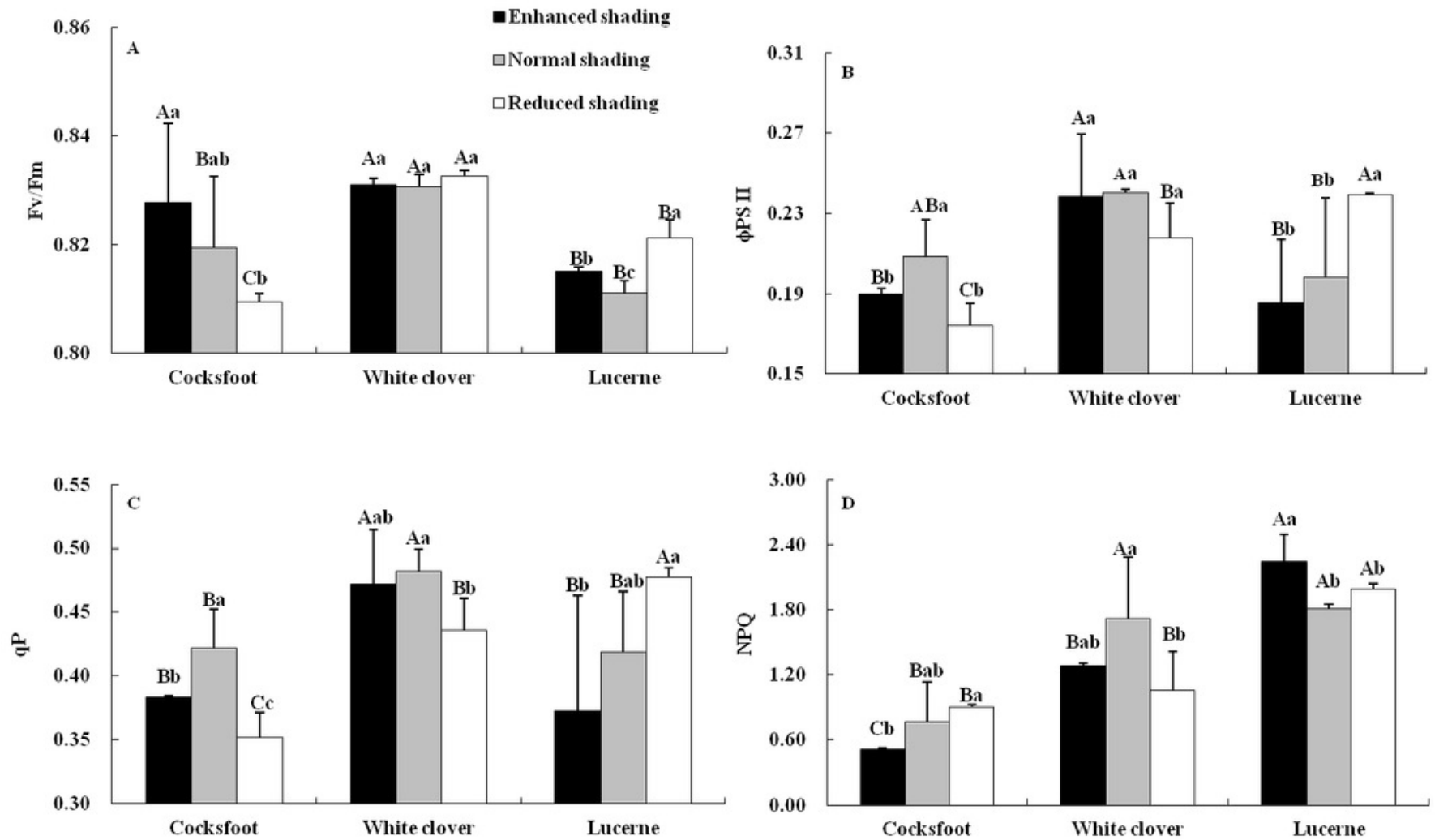

Cocksfoot

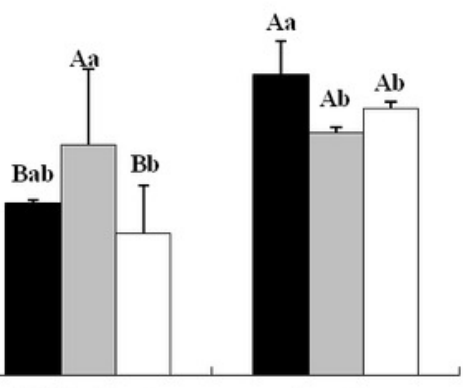

White clover

Lucerne 